\title{
Large-Grain Tin-Rich Perovskite Film for Efficient Solar Cells via Metal Alloying
}

\section{Technique}

\author{
Mohammad Mahdi Tavakoli ${ }^{1,2}$, Shaik Mohammed Zakeeruddin², ${ }^{2}$ ichael Grätzel ${ }^{2}$, Zhiyong Fan ${ }^{1 *}$ \\ ${ }^{1}$ Department of Electronics and Computer Engineering, The Hong Kong University of Science and \\ Technology, Hong Kong, Clear Water Bay, Kowloon, Hong Kong SAR, China \\ ${ }^{2}$ Institut des Sciences et Ingénierie Chimiques, Ecole Polytechnique Fédérale de Lausanne (EPFL), \\ EPFL-BCH, CH-1015 Lausanne, Switzerland \\ * Corresponding author: eezfan@ust.hk
}

Fast progress on lead halide perovskite solar cells has been achieved with current record-high energy conversion efficiency of over $22 \%$. Despite, the presence of lead $(\mathrm{Pb})$ in perovskite composition as a toxic element still remains a major issue for large scaled deployment. In this work, we present a novel and facile technique to fabricate tin $(\mathrm{Sn})$-rich perovskite film using metal precursor and alloying technique. Specially, we deposit the metal precursors ( $\mathrm{Sn}, \mathrm{Pb}$, and $\mathrm{Pb} / \mathrm{Sn}$ alloys) with different thicknesses and compositions on $\mathrm{TiO}_{2}$-coated ITO glass. Subsequently, the perovskite films are formed as a result of the reaction between metal precursors and methylammonium iodide (MAI) vapour in a chemical vapour deposition (CVD) process carried out at $185^{\circ} \mathrm{C}$. We find that in this approach, the $\mathrm{Pb} / \mathrm{Sn}$ precursors first are converted to $(\mathrm{Pb} / \mathrm{Sn}) \mathrm{I}_{2}$ and further reaction with MAI vapour leads to formation of perovskite films. By using $\mathrm{Pb}-\mathrm{Sn}$ eutectic alloy, perovskite films with large grain size up to $5 \mu \mathrm{m}$ can be grown directly from liquid phase metal. Consequently, using alloying technique and this unique growth mechanism, we demonstrate a lesstoxic and efficient perovskite solar cell with power conversion efficiency (PCE) of $14.04 \%$, while pure Sn and $\mathrm{Pb}$ perovskite solar cells prepared in this manner yield PCEs of $4.62 \%$ and $14.21 \%$, respectively. We found that this alloying technique can open up a new direction to further study different alloys system (binary or ternary alloys) with even lower melting point. 
In the past few years, organic-inorganic perovskite solar cells have been improved drastically in terms of solar to electric power conversion efficiency (PCE) and stability. ${ }^{1-4}$ Besides high device performance, low fabrication cost and temperature as well as the tunabilty of their composition and band gap make this group of semiconductors highly promising for optoelectronics applications.$^{5-9}$ Device architecture design, material compositional engineering, and optimization of fabrication process of perovskite materials have been explored in the past years to enhance the efficiency as well as stability of solar cell devices. ${ }^{10-16}$ Nevertheless, the lead toxicity is still a key problem for commercialization of perovskite solar cells. So far, many research groups have explored replacement of $\mathrm{Pb}$ by other metals such as $\mathrm{Sn}, \mathrm{In}, \mathrm{Sr}, \mathrm{Bi}, \mathrm{Al}, \mathrm{Ge}, \mathrm{Au}$, etc., into the perovskite structure. ${ }^{17-20}$ However, to completely substitute $\mathrm{Pb}$ with other metals still remains a big challenge. Meanwhile, studies showed that adding these elements at a low concentration to the perovskite can improve their crystallinity and performance of solar cell devices. ${ }^{21} \mathrm{Up}$ to now, Sn is the only choice that can to completely replace $\mathrm{Pb}$ inside the perovskite lattice and Sn-based perovskite solar cell with efficiency around $6 \%$ has been reported. Thus, large efforts are still needed to realize Sn-based devices whose performance is comparable with $\mathrm{Pb}$-based ones. ${ }^{22-26}$ Replacement of $\mathrm{Pb}$ by $\mathrm{Sn}$ causes only a small perturbation in the lattice due to their similar ionic radii. It shifts the absorption of the perovskite to the near infra-red range decreasing its band gap down to below $1.3 \mathrm{eV} \cdot{ }^{27,28}$ Nevertheless, the poor stability of Sn-based perovskite is still a big challenge for fabricating $\mathrm{Pb}$-free solar cell devices, due to fast oxidation of $\mathrm{Sn}^{2+}$ to $\mathrm{Sn}^{4+}$ and moisture attack. ${ }^{29-31}$ In this regard, a binary metal perovskite $\mathrm{MAPb} \mathrm{Sn}_{1-\mathrm{x}} \mathrm{I}_{3}$ $(0<\mathrm{x}<1)$, i.e., partial replacement of $\mathrm{Pb}$ by $\mathrm{Sn}$, is a viable way to fabricate more stable solar cells with decent efficiency compared with pure Sn perovskites. In the past few years, some research groups reported a binary $\mathrm{Pb}-\mathrm{Sn}$ perovskite solar cell with a maximum efficiency up to $7.27 \% .{ }^{31-35}$ Zhao et al. ${ }^{36}$ fabricated binary $\mathrm{Pb}-\mathrm{Sn}$ perovskite solar cells devices using solution process with different concentrations of $\mathrm{Sn}(0$ $100 \%)$ and they have reported a Sn-rich $(60 \% \mathrm{Sn})$ perovskite solar cell device with $10 \%$ efficiency which is higher than other concentrations of Sn metal. In addition, Li et al. ${ }^{37}$ reported a 50\%-Sn based perovskite solar cell with $13.6 \%$ PCE using a two-step spin coating solution, which is the highest performance among 
$\mathrm{MA}\left(\mathrm{Sn}_{\mathrm{x}} \mathrm{Pb}_{1-\mathrm{x}}\right) \mathrm{I}_{3}$ reported to date on single MA cation-based perovskite solar cell devices. Recently, few research groups reported $\mathrm{Pb}-\mathrm{Sn}$ perovskite solar cells with higher performance and stability based on triple cations formulations, using a mixture of cesium, formamidinium, and methylammonium, which are good candidates for tandem solar cell application. ${ }^{38,39}$ Herein, we propose a novel solvent-free fabrication process for perovskite solar cells based on chemical vapour deposition (CVD) technique. The perovskite film is formed as a result of reaction between a $\mathrm{Pb} / \mathrm{Sn}$ metal alloy and methylammonium iodide (MAI) inside a tubular furnace at $185{ }^{\circ} \mathrm{C}$ for 40 min under Argon atmosphere. In particular, we fabricate perovskite film exhibiting large grain size and excellent crystallinity from a liquid $\mathrm{Pb} / \mathrm{Sn}$ alloy with the eutectic composition of $62 \mathrm{wt} \% \mathrm{Sn}$. By judicious selection of metal precursors and alloying technique we have achieved good control of the composition, morphology and crystallinity of the perovskite film. Finally, we realize a Sn-rich perovskite solar cell with $14.04 \%$ PCE, which is the highest performance so far for Sn-rich single cation $\mathrm{MA}\left(\mathrm{Sn}_{\mathrm{x}} \mathrm{Pb}_{1-\mathrm{x}}\right) \mathrm{I}_{3}$.

\section{Results and Discussions}

Figure 1 shows the phase diagram of the $\mathrm{Pb}-\mathrm{Sn}$ system $^{40}$ and the schematics for the reaction mechanism occurring in our approach. We introduce a new and facile method to fabricate perovskite film directly from $\mathrm{Pb}$ or $\mathrm{Sn}$ metal and their alloys using a tubular CVD furnace, as shown in Figure 1b. Particularly, 5 alloys with $0,30,62,80$, and 100 weight percentages of $\mathrm{Sn}$ are selected and deposited on $\mathrm{TiO}_{2}$-coated ITO glasses. The alloys are made by sequential deposition of two separated layers of $\mathrm{Pb}$ and $\mathrm{Sn}$, with different thicknesses. The composition of the alloys was determined by Energy-dispersive X-ray spectroscopy (EDAX) analysis, as indicated in Table 1. In order to fabricate the perovskite film, the metal-coated substrates were placed inside the CVD tube furnace besides the MAI powder (Figure 1b) and the reaction was performed at $185{ }^{\circ} \mathrm{C}$ for $40 \mathrm{~min}$ in Argon atmosphere. As seen in Figures $1 \mathrm{c}_{1-3}$, the reaction proceeds via two steps leading to formation of perovskite film according to the following equations: ${ }^{41}$

$$
\begin{aligned}
& 2 \mathrm{CH}_{3} \mathrm{NH}_{3} \mathrm{I}+\mathrm{Pb} / \mathrm{Sn} \rightarrow(\mathrm{Pb} / \mathrm{Sn}) \mathrm{I}_{2}+2 \mathrm{CH}_{3} \mathrm{NH}_{2}+\mathrm{H}_{2} \\
& \mathrm{PbI}_{2} / \mathrm{SnI}_{2}+\mathrm{CH}_{3} \mathrm{NH}_{3} \mathrm{I} \rightarrow \mathrm{CH}_{3} \mathrm{NH}_{3}(\mathrm{~Pb} / \mathrm{Sn}) \mathrm{I}_{3}
\end{aligned}
$$


Corresponding to the overall reaction

$$
3 \mathrm{CH}_{3} \mathrm{NH}_{3} \mathrm{I}+\mathrm{Pb} / \mathrm{Sn} \rightarrow \mathrm{CH}_{3} \mathrm{NH}_{3}(\mathrm{~Pb} / \mathrm{Sn}) \mathrm{I}_{3}+2 \mathrm{CH}_{3} \mathrm{NH}_{2}+\mathrm{H}_{2}
$$

In reaction $1, \mathrm{MAI}$ reacts with $\mathrm{Pb} / \mathrm{Sn}$ (Figure 1c), resulting in formation of an intermediate phase, i.e., $(\mathrm{Pb} / \mathrm{Sn}) \mathrm{I}_{2}$ film. Subsequently, the perovskite film is formed via the reaction between MAI and $(\mathrm{Pb} / \mathrm{Sn}) \mathrm{I}_{2}$ (Figure $1 \mathrm{~b}, \mathrm{c}$ ). Equation 3 presents the overall stoichiometry of the conversion process. Interestingly, this reaction leads to large volume increase by a factor of 8.35 and 4.60 for $\mathrm{Pb}$ and $\mathrm{Sn}$ perovskite, respectively. ${ }^{42-44}$ The thickness of metal precursors for fabrication of perovskite film is controlled according to these volume ratios. In order to further-study the thickness of perovskite film based on different compositions, we have deposited metal and alloy precursors with different thicknesses, i.e. 15, 30, 45, and $60 \mathrm{~nm}$, on silicon wafers. After completion of the reaction, the final thickness of perovskite films was measured using an Alpha-step 200 (Tencor) profilometer. Figure S1 shows the results of this test are, confirming that the volume increase accompanying the conversion of $\mathrm{Pb}$-based films is larger than $\mathrm{Sn}$ based ones. Thus, by increasing the amount of $\mathrm{Sn}$ in the precursor, the final thickness of perovskite film is decreased. These results are in good agreement with the calculated values of volume increase for pure $\mathrm{Pb}$ and Sn compositions. In fact, the key advantage of our film growth approach here is that the perovskite film can be directly grown from a liquid metal phase. As shown in phase diagram in Figure 1a, increasing the $\mathrm{Sn}$ concentration decreases the melting point of $\mathrm{Pb}-\mathrm{Sn}$ alloys till the minimum of $183{ }^{\circ} \mathrm{C}$ is reached at the eutectic composition in the $\mathrm{Pb}-\mathrm{Sn}$ phase diagram. ${ }^{31}$ Since the reaction temperature in our CVD process is $185^{\circ} \mathrm{C}$ the perovskite is formed directly from molten eutectic alloy film. In this case, all atoms and molecules can find energetic favourable positions to pack up and form large crystals. Figures 2 and S2 depict the photographs and top-view SEM images of metal, intermediate phase, and perovskite films with different Sn-contents. As seen in Figure 2a1-a3, the color of sample changes from greyish to yellow for the intermediate phase and finally dark brownish (perovskite film) depending on the reaction time. Figures $2 \mathrm{~b}_{1}$, $2 \mathrm{c}_{1}$, and $2 \mathrm{~d}_{1}$ show the morphology of pure $\mathrm{Pb}, \mathrm{Pb} / \mathrm{Sn}$ eutectic alloy, and pure $\mathrm{Sn}$ metal films, respectively. The metal films consist of many separated islands. Since they are porous, the MAI molecules can easily 
diffuse inside the metal lattice, speeding up their conversion to perovskite at the reaction temperature of $185^{\circ} \mathrm{C}$. The SEM images of intermediate phase illustrate $(\mathrm{Pb} / \mathrm{Sn}) \mathrm{I}_{2}$ films with flake-shape morphology and hexagonal structure, as shown in Figures $2 b_{2}, 2 c_{2}, 2 d_{2}$, and Figure S3 with high resolution. By increasing the reaction time, perovskite films with high crystallinity are formed as shown in Figures $2 \mathrm{~b}_{3}, 2 \mathrm{c}_{3}$, and $2 \mathrm{~d}_{3}$. Figure $2 b_{3}, 2 c_{3}$ and $2 d_{3}$ show that the film grown from the eutectic $\mathrm{Pb} / \mathrm{Sn}$ alloy has grain sizes up to $5 \mu \mathrm{m}$ which is much larger than the film grown from pure $\mathrm{Pb}$ and $\mathrm{Sn}$ metals. This is due to the fact that the reaction of MAI occurs here with the liquid metal favouring the formation of large size crystals. As shown in Figure $2 \mathrm{c}_{2}$, the number of $\mathrm{Pb} / \mathrm{SnI}_{2}$ nucleuses for eutectic alloy composition is less than other compositions, resulting in lower number of grains with larger size. This is due to higher nucleation energy for eutectic alloy in liquid phase. This phenomenon can certainly be exploited to fabricate perovskite film with high quality crystal structure. As shown in Figure S2, the grain size of perovskite films for other two alloys is slightly larger than pure lead and tin perovskite film. Because for these alloys, the regions located at over $183{ }^{\circ} \mathrm{C}$ (Figure 1a) are mushy zone with semi-solid phase and thus, the reaction occurs faster due to higher diffusion rate of atoms, resulting in larger grains as compare to pure $\mathrm{Pb}$ and $\mathrm{Sn}$ ones. Figure $\mathrm{S} 4$ shows different growth steps of perovskite film based on eutectic alloy. As seen in Figure S4c, the initial nucleases are big enough in order to form perovskite film with large grain size. It is worth pointing out that the grain size of perovskite film is increased by increasing the reaction temperature; however, the film quality is decreased due to the faster decomposition of perovskite layer, as illustrated in Figure S5. The EDAX elemental mapping of lead, tin, iodide, and carbon in Figure S6 confirms their uniform distribution in perovskite films based on eutectic alloy. Furthermore, the EDAX analysis proves that the relative amount of $\mathrm{Pb}$ and $\mathrm{Sn}$ in the perovskite remains the same as the eutectic alloy.

In addition, we examined the oxidation of Sn-based alloys after conversion to the perovskite using X-ray photoelectron spectroscopy (XPS). Figure S7 shows the high-resolution spectrum of Sn 3d, after deconvolution. The results demonstrate that $\mathrm{Sn}^{2+}$ is easily oxidized into $\mathrm{Sn}^{4+}$ due to the unstable nature of Sn (II)-based perovskite. After deconvolution of the spectra, there are four peaks located at $485.8 \mathrm{eV}$ and 
$495.6 \mathrm{eV}$ for $\mathrm{Sn}^{2+}$ and $486.8 \mathrm{eV}$ and $496.5 \mathrm{eV}$ for $\mathrm{Sn}^{4+}$. As seen in Figure $\mathrm{S}$, there is a tendency that the intensity of $\mathrm{Sn}^{2+}$ peak is decreased, whereas the intensity of $\mathrm{Sn}^{4+}$ peak is increased upon augmenting the $\mathrm{Sn}$ level in the perovskite composition. This suggests that the presence of $\mathrm{Pb}$ (II) stabilizes $\mathrm{Sn}$ in its $2^{+}$state. In fact, the main reason for observing $\mathrm{Sn}^{4+}$ peak in the spectrum is the exposure of Sn-based films to the air before XPS measurement, as previously reported in the literature. ${ }^{36-37}$

In order to further study the composition of the perovskite film fabricated by CVD method, X-ray diffraction patterns were recorded of metal films, intermediate phases after 20 min reaction time, and perovskite films formed from the reaction between metal precursor and MAI after 40 min, for pure $\mathrm{Pb}$, eutectic alloy, and pure Sn, as shown in Figure 3. Initially the pattern of the eutectic alloy shows peaks at $32^{\circ}, 36^{\circ}, 44^{\circ}$, and $52^{\circ}$ from $\mathrm{Pb}(111) / \mathrm{Sn}(101), \mathrm{Pb}(200), \mathrm{Sn}(220)$, and $\mathrm{Pb}(220)$ facets, respectively. ${ }^{42}$ After 20 min reaction for pure $\mathrm{Pb}$, eutectic alloy, and pure $\mathrm{Sn}$, strong peaks located at $12.6^{\circ}$ appeared, indicating the presence of $(\mathrm{Pb} / \mathrm{Sn}) \mathrm{I}_{2}$ phases formed as an intermediate product during the CVD reaction, ${ }^{42}$ as expressed by reaction 1 . New patterns appeared after 40 min reaction time for all compositions with the main XRD reflections located at $14^{\circ}, 28^{\circ}$, and $43^{\circ}$. These arose from the (110), (220), and (330) planes of the perovskite phase with tetragonal crystal structure, respectively. ${ }^{36}$ Moreover, the lack of $(\mathrm{Pb} / \mathrm{Sn}) \mathrm{I}_{2}$ peaks $\left(12.6^{\circ}\right)$ indicates that the conversion of the metal iodide to perovskite by MAI is stoichiometric. Notably, the perovskite film formed from eutectic alloy shows a single crystal-like XRD pattern with dominant $\{110\}$ growth orientation. This is consistent with the aforementioned unique growth directly from the molten eutectic alloy.

To gain a better understanding of the role of Sn element at different concentrations within the perovskite structure, the absorbance, steady-state and transient photoluminescence (PL) spectra of samples were measured showing in Figure 4. Figure 4a shows that the perovskite absorption edge shifts to longer wavelengths by substituting $\mathrm{Pb}^{2+}$ with $\mathrm{Sn}^{2}$ decreasing the band gap. ${ }^{31,32}$ Above $80 \% \mathrm{Sn}$, the absorption edge decreases from 1010 to $950 \mathrm{~nm}$, resulting in a band gap of $1.28 \mathrm{eV}$ for pure Sn-based perovskite film. A similar trend appears in the PL spectra, as illustrated in Figure 4b, where the PL spectra of both $62 \%$ and 
$80 \%$ Sn perovskite films are red-shifted as compared to the pure $\mathrm{Sn}$ formulation, which is in good agreement with the absorption results. Such behaviour deviates from Vegard's law ${ }^{29}$ and has been attributed to the competition between the spin-orbital coupling of $\mathrm{Pb}$ and $\mathrm{Sn}$ ions in the perovskite lattice. The difference in their ion radii causes lattice distortions which affect the extend of coupling depending on the composition of the mixed phase. ${ }^{37}$ To further study the effect of Sn concentration and alloying technique on optical properties, transient PL intensity profiles of perovskite films are measured and shown in Figure 4c with the fitting parameters illustrated in Table S1. The results indicate that the PL lifetime of large grain perovskite film with $62 \% \mathrm{Sn}$ concentration is around $91 \mathrm{~ns}$ which is longer than that observed for the other perovskite compositions. Thus, the perovskite film with large grain size derived from the eutectic alloy shows the longest PL lifetime. In fact, the PL decay lifetime is decreased down to $3.6 \mathrm{~ns}$ for the pure Sn perovskite film. This is likely to be the reasons for the lower performance of perovskite solar cell devices with high concentration of Sn. These results confirm that by controlling the film crystallinity and grain size, the PL lifetime of perovskite film with high concentration of Sn can be enhanced drastically.

The photovoltaic (PV) properties of perovskite films with different concentrations of Sn fabricated by the CVD process using metal precursors have been evaluated to further investigate the role of $\mathrm{Sn}$ in perovskite lattice, as demonstrated in Figure 5. The cross-sectional SEM image of perovskite solar cell based on $\mathrm{Pb}$ Sn alloy is shown in Figure 5a. The device architecture consists of an ITO glass covered by a 40 nm-thick of $\mathrm{TiO}_{2}$ layer as blocking layer, a perovskite film with thickness of $\sim 370 \mathrm{~nm}$, a layer of spiro-OMeTAD as hole transfer material $(\sim 150 \mathrm{~nm})$, and $100 \mathrm{~nm}$-thick gold as contact electrode. Figure $5 \mathrm{~b}$ shows the current density-voltage $(J-V)$ curves of perovskite solar cells with different concentrations of Sn under simulated (AM1.5G) solar irradiation. The device performance parameters are summarized in Table 2. Figure S8 shows the statistical distribution of the photovoltaic metrics (open circuit voltage $\left(V_{o c}\right)$, short circuit current density $\left(J_{s c}\right)$, fill factor $(F F)$, and power conversion efficiency $\left.(\mathrm{PCE})\right)$ of devices with different Sn contents. For each Sn composition, we measured 7 devices to obtain the statistics. As seen in Table 2, the highest 
and lowest efficiencies are from pure Pb-based and pure Sn-based perovskite solar cells with PCEs reaching $14.21 \%$ and $4.62 \%$, respectively. Interestingly, among the binary solar cells, eutectic alloy-based device obtains the best performance reaching $14.04 \%$, with a $V_{o c}$ of 0.796 , high $J_{s c}$ of $25.5 \mathrm{~mA} / \mathrm{cm}^{2}$, and $F F$ of $69.2 \%$, which is comparable with pure $\mathrm{Pb}$-based device. The perovskite device with the lowest band gap of $1.22 \mathrm{eV}$, i.e., $80 \mathrm{wt} \%$ of $\mathrm{Sn}$ content shows a PCE of $7.07 \%$. To the best of our knowledge, these binary $\mathrm{Pb}-\mathrm{Sn}$ devices are among the highest efficiencies achieved so far for $\mathrm{Sn}$-rich binary $\mathrm{Sn} / \mathrm{Pb}$ metal perovskite solar cells. ${ }^{32-35}$ Figure S9 demonstrates hysteresis data for eutectic alloy-based device, indicating a negligible hysteresis value. In addition to PV measurement results, the external quantum efficiency (EQE) spectra, shown in Figure 5c, are consistent with the absorbance and $J-V$ results. The calculated $J_{s c}$ from EQE curves (Table 2) well matches with PV results. In fact, the devices with Sn contents show lower EQE at longer wavelengths due to lower absorption in the IR range. Among these devices, the eutectic alloybased one exhibits the highest absorption in IR region due to the better crystallinity, resulting in a high $J_{s c}$ reaching $25.5 \mathrm{~mA} / \mathrm{cm}^{2}$. Figure 6a depicts that the best performing perovskite device based on eutectic alloy reaches a stabilized power output of $13.1 \%$ (inset graph), which is calculated from scan-rate independent maximum power point (MPP) tracking for 60 seconds. The stability test of this device compared with pure $\mathrm{Pb}$-based one after packaging with epoxy is shown in Figure 6b. After 100 hours under continuous light illumination, the eutectic alloy-based device still maintained $90 \%$ of its initial PCE, which is comparable with the pure Pb-based device. Figure $6 \mathrm{c}$ shows the $J-V$ curves of perovskite film with different thicknesses $(250,300,370,400,450 \mathrm{~nm})$ for devices based on eutectic alloy. In fact, the thickness of films in CVD method has been controlled by thickness of metal precursors. The results indicate that perovskite film with $370 \mathrm{~nm}$ thickness is the optimum value due to the higher $J_{s c}$ and PCE. Generally, in a typical solar cell device, when the thickness of absorber layer is increased, the $\mathrm{J}_{\mathrm{sc}}$ increases due to more light absorption leading to an increase of $\mathrm{V}_{\mathrm{oc}}\left(\mathrm{V}_{\mathrm{oc}} \sim \ln \left(\mathrm{J}_{\mathrm{sc}} / \mathrm{J}_{0}\right)\right)$. However, upon increasing the thickness more than an optimum value, both $\mathrm{J}_{\mathrm{sc}}$ and $\mathrm{V}_{\mathrm{oc}}$ start to drop due to Shockley-Reed-Hall recombination. ${ }^{45,46}$ 
Figure 6d shows the effect of the CVD processing temperature on the PCE of perovskite solar cells. In this experiment, the reaction has completed at $155,170,185,200$, and $215{ }^{\circ} \mathrm{C}$ temperatures in the CVD furnace. The PV results demonstrate that the formation of perovskite film at $185^{\circ} \mathrm{C}$ provides the best film quality, resulting in the highest $J_{s c}$ and PCE values.

\section{Conclusions}

In conclusion, herein we demonstrate a novel method for producing metal halide perovskites based on the direct conversion of metallic $\mathrm{Sn}, \mathrm{Pb}$ or $\mathrm{Sn}-\mathrm{Pb}$ alloys by chemical reaction with MAI vapour. And $\mathrm{Sn}$-rich mixed $\mathrm{Sn} / \mathrm{Pb}$ perovskite films of high quality crystals and large grains size over $5 \mu \mathrm{m}$ has been successfully fabricated. In this unique approach, the perovskite film is formed directly from metal precursors through a two-step reaction. Using EDAX analysis and $\mathrm{XRD}$ tests, it is shows that $\mathrm{PbI}_{2} / \mathrm{SnI}_{2}$ is formed as the intermediate phase of the reaction between metal precursors and MAI molecules. We have grown large grain size perovskite film of high quality from the liquid phase of a $\mathrm{Pb}-\mathrm{Sn}$ eutectic alloy (62wt\% $\mathrm{Sn}$ ) by exposure to gaseous MAI at $185^{\circ} \mathrm{C}$. The optical measurements show that replacing $\mathrm{Pb}$ ions by $\mathrm{Sn}$ ions (from 0 to $80 \mathrm{wt} \%$ Sn content) reduces the optical band gap of perovskite films from 1.55 to $1.22 \mathrm{eV}$. Upon augmenting the Sn content further from 80 to $100 \mathrm{wt} \%$ the band gap increases again to $1.32 \mathrm{~V}$. Perovskite films fabricated by our new method show a PCE of $14.21 \%$ and $4.62 \%$ for pure $\mathrm{Pb}$ and pure $\mathrm{Sn}$ based perovskite solar cells, respectively. Remarkably, a perovskite solar cell based on the $\mathrm{Pb}$-Sn eutectic alloy reaches a PCE of 14.04\%, which is among the highest efficiencies for Sn-rich devices. Overall, the approach developed here can enable a new and facile fabrication process for a wide variety of perovskite films with different compositions. In fact, the developed alloying technique can be further used to explore the role of different metal elements on perovskite films using various binary or ternary alloy systems, suggesting a new direction of perovskite research.

\section{Experimental Section}

\section{Synthesis of $\mathrm{TiO}_{2}$ nanocrystals}


A non-hydrolytic sol-gel method was employed to synthesize $\mathrm{TiO}_{2}$ nanocrytals, as reported elsewhere. ${ }^{47}$ Briefly, first $\mathrm{TiCl}_{4}(0.5 \mathrm{~mL})$ was added slowly under stirring to ethanol $(2 \mathrm{~mL})$, followed by addition of 10 $\mathrm{mL}$ benzyl alcohol to obtain a yellowish solution. This was heated up to $80{ }^{\circ} \mathrm{C}$ for 5 hours resulting in the formation of a slightly milky suspension. Subsequently, $200 \mathrm{~mL}$ diethyl ether was added to the suspension, followed by centrifuging in order to collect the whitish precipitate. The final product was washed with absolute ethanol and diethyl ether several times using a centrifuge. Finally, we dispersed the $\mathrm{TiO}_{2}$ nanocrystals in ethanol at a concentration of $\sim 7 \mathrm{mg} / \mathrm{mL}$. Finally, titanium bis-acetylacetonate (TiACAC) $(15 \mu \mathrm{L} / \mathrm{mL})$ was added into the suspension to stabilize the $\mathrm{TiO}_{2}$ nanocrystals.

\section{Device fabrication}

ITO glass substrates were cleaned in acetone, detergent, deionised (DI) water, and ethanol using ultrasonic treatment for $20 \mathrm{~min}$, respectively. After $20 \mathrm{~min}$ of ozone plasma treatment, a $40 \mathrm{~nm}$-thick $\mathrm{TiO}_{2}$ layer was spin-coated on the ITO substrates using the colloidal $\mathrm{TiO}_{2}$ solution $(2500 \mathrm{rpm}$, for $35 \mathrm{~s})$, followed by annealing at $150{ }^{\circ} \mathrm{C}$ for $30 \mathrm{~min}$ in ambient air. This process was repeated twice. Then, $\mathrm{Pb} / \mathrm{Sn}$ metals with different thicknesses were thermally evaporated on the $\mathrm{TiO}_{2}$-coated ITO glasses. The alloy composition was controlled by the thickness of Tin and Lead films. In this case, $\mathrm{Pb}$ and $\mathrm{Sn}$ metal were evaporated separately in two steps without breaking the vacuum. The alloys were formed by heating the substrates up to their melting point in order to get a uniform alloy composition. The composition was controlled by EDAX analysis. Subsequently the substrates with metal or alloy films were transferred into a tubular CVD furnace ( 1 inch quartz tube) and placed into two small quartz containers at the center of tube close to the thermocouple. The MAI powder was spread inside the small tube beside the substrates. Thereafter, the reaction between MAI and $\mathrm{Pb} / \mathrm{Sn}$-coated substrates was performed at $185^{\circ} \mathrm{C}$ for 40 min under continuous Argon flow at a rate of 100 standard cubic centimetres per minute (SCCM)). After completion of the reaction, the samples were transferred into a nitrogen glovebox. Then, the surface of perovskite film was treated with isopropanol (IPA) containing poly(4-Vinylpyridine)(PVP) with concentration of $0.1 \mathrm{mg} / 1 \mathrm{~mL}$ by spin coating at $4000 \mathrm{rpm}$ for $30 \mathrm{~s}$. This step is necessary to passivate the perovskite interface. ${ }^{48}$ In fact, a 
thin layer of PVP can help to protect Sn-based perovskite film from spiro solution and make a more stable film. In order to complete the device, spiro-OMeTAD (Lumtec, Taiwan) solution (80 $\mathrm{mg} / 1 \mathrm{~mL}$ chlorobenzene) containing $17.5 \mu \mathrm{Li}$-bis(trifluoromethanesulfonyl) imide (Li-TFSI)/acetonitrile (500 mg/1 $\mathrm{ml}$ ) and $28.5 \mu \mathrm{TBP}$ was spin coated onto the perovskite film at $4000 \mathrm{rpm}$ for $20 \mathrm{~s}$, followed by thermal evaporation of $100 \mathrm{~nm}$-thick gold as an electrode. The active area of device was $0.1 \mathrm{~cm}^{2}$.

\section{Film characterization}

Field-emission scanning electron microscopy (FESEM, Hitachi S4160, Japan) equipped with energydispersive X-ray spectroscopy (EDAX) was used to study the thickness, morphology and composition of perovskite device. X-ray diffraction (Bruker D8 X-ray Diffractometer, USA) utilizing a $\mathrm{Cu} K \alpha$ radiation was performed for phase characterization. X-ray photoelectron spectroscopy (XPS) measurements were performed by using a hemispherical analyzer and an $\mathrm{Al} \mathrm{K \alpha}$ X-ray source $(1486.6 \mathrm{eV})$ operated at $10^{-7} \mathrm{~Pa}$. A Varian Carry 500 spectrometer (Varian, USA) was used to record the optical absorption of samples. Steady-state photoluminescence spectra were measured on an Edinburgh Instruments FLS920P fluorescence spectrometer. A picosecond pulsed diode laser (EPL-405, excitation wavelength $405 \mathrm{~nm}$, pulse width 49 ps) was employed for lifetime measurements. PL decay curves were analyzed using fitting a stretched exponential function $\mathrm{I}(\mathrm{t})=\mathrm{I} \exp \left(-(\mathrm{t} / \tau)^{\beta}\right)$, where $\tau$ is the decay time and $\beta$ is a stretch parameter. All film characterizations were performed in air after encapsulation due to Sn oxidation.

\section{Device characterization}

The solar devices were measured at AM1.5G simulated by an Abet Class AAB Sun 2000 simulator (with intensity of $100 \mathrm{mWcm}^{-2}$ ). The illumination power on the samples was calibrated by using a standard $\mathrm{Si}$ solar cell. A 2400 Series Source Meter (Keithley, USA) instrument was employed to measure the current density-voltage $(J-V)$ data. The voltage range for $J-V$ sweeps was between -1.2 and $0 \mathrm{~V}$, with a step size of $0.005 \mathrm{~V}$ and a delay time of $200 \mathrm{~ms}$ at each point. For external quantum efficiency (EQE) spectra, a constant white light bias of nearly $5 \mathrm{~mW} . \mathrm{cm}^{-2}$ using Oriel QE-PV-SI (Newport Corporation) was used. All devices were measured inside a nitrogen glovebox. 


\section{Supporting Information}

Supporting information is available from the Wiley online library or from the author.

\section{Acknowledgements}

This work was supported by the General Research Fund (project16237816) from the Hong Kong Research Grant Council, the Hong Kong Innovation and Technology Fund (ITS/362/14FP) from the Innovation and Technology Commission, State Key Laboratory on Advanced Displays and Optoelectronics at HKUST and National Natural Science Foundation of China (project51672231). Also, the authors would like to thank the support from the Center for 1D/2D Quantum Materials at HKUST. MG and SMZ thank funding from the European Union's Horizon 2020 programme, through a FET Open research and innovation action under grant agreement No 687008 .

\section{Conflict of Interest}

The authors declare no conflict of interest.

\section{Keywords}

Chemical vapour deposition, metal precursor, alloy, perovskite, solar cell.

\section{References}

[1] J. W. Lee, H. S. Kim, N. G. Park, Acc. Chem. Res. 2016, 49, 311.

[2] W. S. Yang, B. W. Park, E. H. Jung, N. J. Jeon, Y. C. Kim, D. U. Lee, S. S. Shin, J. Seo, E. K. Kim, J. H. Noh, S. I. Seok, Science, 2017, 356, 1376.

[3] H. J. Snaith, J. Phys. Chem. Lett. 2013, 4, 3623.

[4] M. Liu, M. B. Johnston, H. J. Snaith, Nature, 2013, 501, 395.

[5] M. M. Tavakoli, R. Tavakoli, Z. Nourbakhsh, A. Waleed, U. S. Virk, Z. Fan, Adv. Mater. Interfaces, 2016, 3, 1500790. 
[6] J. Burschka, N. Pellet, S. J. Moon, R. Humphry-Baker, P. Gao, M. K. Nazeeruddin, M. Grätzel, Nature, 2013, 499, 316.

[7] M. M. Tavakoli, L. Gu, Y. Gao, C. Reckmeier, J. He, A. L. Rogach, Y. Yao, Z. Fan, Sci. Rep. 2015, 5, 14083.

[8] M. M. Tavakoli, Q. Lin, S. F. Leung, G.C. Lui, H. Lu, L. Li, B. Xiang, Z. Fan, Nanoscale, 2016, $8,4276$.

[9] H. S. Kim, J. W. Lee, N. Yantara, P. P. Boix, S. A. Kulkarni, S. Mhaisalkar, M. Grätzel, N. G. Park, Nano Lett. 2013, 13, 2412.

[10] J. Teuscher, A. Ulianov, O. Müntener, M. Grätzel, N. Tétreault, Chem. Sus. Chem. 2015, 8, 3847.

[11] M. M. Tavakoli, K. H. Tsui, Q. Zhang, J. He, Y. Yao, D. Li, Z. Fan, ACS Nano, 2015, 9, 10287.

[12] G. E. Eperon, V. M. Burlakov, P. Docampo, A. Goriely, H. J. Snaith, Adv. Function. Mater. 2014, 24, 151.

[13] L. Wang, C. McCleese, A. Kovalsky, Y. Zhao, C. Burda, JACS, 2014, 136, 12205.

[14] G. Longo, L. Gil-Escrig, M. J. Degen, M. Sessolo, H. J. Bolink, Chem. Commun. 2015, 51, 7376.

[15] L. Etgar, P. Gao, Z. Xue, Q. Peng, A. K. Chandiran, B. Liu, M. K. Nazeeruddin, M. Grätzel, JACS, 2012, 134, 17396.

[16] M. M. Tavakoli, A. Simchi, X. Mo, Z. Fan, Mater. Chem. Front. 2017, DOI:10.1039/c6qm00379f.

[17] D. Pérez-del-Rey, D. Forgács, E. M. Hutter, T. J. Savenije, D. Nordlund, P. Schulz, J. J. Berry, M. Sessolo, H. J. Bolink, Adv. Mater. 2016, 28, 9839.

[18] J. T. W. Wang, Z. Wang, S. Pathak, W. Zhang, F. Wisnivesky-Rocca-Rivarola, J. Huang, P. K. Nayak, J. B. Patel, H. A. M. Yusof, Y. Vaynzof, R. Zhu, Energy Environ. Sci. 2016, 9, 2892. 
[19] A. L. Abdelhady, M. I. Saidaminov, B. Murali, V. Adinolfi, O. Voznyy, K. Katsiev, E. Alarousu, R. Comin, I. Dursun, L. Sinatra, E. H. Sargent, J. Phys. Chem. Lett. 2016, 7, 295.

[20] T. Krishnamoorthy, H. Ding, C. Yan, W. L. Leong, T. Baikie, Z. Zhang, M. Sherburne, S. Li, M. Asta, N. Mathews, S. G. Mhaisalkar, J. Mater. Chem. A, 2015, 3, 23829.

[21] P. P. Boix, K. Nonomura, N. Mathews, S. G. Mhaisalkar, Mater. Today, 2014, 17, 16.

[22] Y. Takahashi, H. Hasegawa, Y. Takahashi, T. Inabe, J. Solid State Chem. 2013, 205, 39.

[23] C. C. Stoumpos, C. D. Malliakas, M. G. Kanatzidis, Inorganic Chem. 2013, 52, 9019.

[24] I. Chung, J. H. Song, J. Im, J. Androulakis, C. D. Malliakas, H. Li, A. J. Freeman, J. T. Kenney, M. G. Kanatzidis, JACS, 2012, 134, 8579.

[25] F. Hao, C. C. Stoumpos, D. H. Cao, R. P. Chang, M. G. Kanatzidis, Nat. Photon. 2014, 8, 489.

[26] N. K. Noel, S. D. Stranks, A. Abate, C. Wehrenfennig, S. Guarnera, A. A. Haghighirad, A.

Sadhanala, G. E. Eperon, S. K. Pathak, M. B. Johnston, A. Petrozza, Energy Environ. Sci. 2014, 7, 3061.

[27] F. Hao, C. C. Stoumpos, P. Guo, N. Zhou, T. J. Marks, R. P. Chang, M. G. Kanatzidis, JACS, 2014, 137,11445 .

[28] S. J. Lee, S. S. Shin, Y. C. Kim, D. Kim, T. K. Ahn, J. H. Noh, J. Seo, S. I. Seok, J. Am. Chem. Soc, 2016, 138, 3974.

[29] F. Hao, C. C. Stoumpos, R. P. Chang, M. G. Kanatzidis, JACS, 2014, 136, 8094.

[30] Y. Ogomi, A. Morita, S. Tsukamoto, T. Saitho, N. Fujikawa, Q. Shen, T. Toyoda, K. Yoshino, S. S. Pandey, T. Ma, S. Hayase, J. Phys. Chem. Lett. 2014, 5, 1004.

[31] M. M. Tavakoli, R. Tavakoli, P. Davami, H. A. Aashuri, J. Comput. Electron. 2014, 13, 425.

[32] D. H. Cao, C. C. Stoumpos, O. K. Farha, J. T. Hupp, M. G. Kanatzidis, JACS, 2015, 137, 7843.

[33] F. Zuo, S. T. Williams, P. W. Liang, C. C. Chueh, C. Y. Liao, A. K. Y. Jen, Adv. Mater. 2014, 26, 6454.

[34] W. Nie, H. Tsai, R. Asadpour, J. C. Blancon, A. J. Neukirch, G. Gupta, J. J. Crochet, M. Chhowalla, S. Tretiak, M. A. Alam, H. L. Wang, Science, 2015, 347, 522. 
[35] J. Im, C. C. Stoumpos, H. Jin, A. J. Freeman, M. G. Kanatzidis, J. Phys. Chem. Lett. 2015, 6, 3503.

[36] B. Zhao, M. Abdi-Jalebi, M. Tabachnyk, H. Glass, V. S. Kamboj, W. Nie, A. J. Pearson, Y. Puttisong, K. C. Gödel, H. E. Beere, D. A. Ritchie, Adv. Mater. 2017, 29, 1604744.

[37] Y. Li, W. Sun, W. Yan, S. Ye, H. Rao, H. Peng, Z. Zhao, Z. Bian, Z. Liu, H. Zhou, C. Huang, Adv. Energy Mater. 2016, 6, 1601353.

[38] R. Prasanna, A. Gold-Parker, T. Leijtens, B. Conings, A. Babayigit, H. G. Boyen, M. F. Toney, M. D. McGehee, JACS, 2017, 139, 11117.

[39] A. Rajagopal, Z. Yang, S. B. Jo, I. L. Braly, P. W. Liang, H. W. Hillhouse, A. K. Y. Jen, $A d v$. Mater. 2017, 29, 1702140.

[40] I. Karakaya, W. T. Thompson, J. Phase Equilibria, 1988, 9, 144.

[41] M. M. Tavakoli, A. Waleed, L. Gu, D. Zhang, R. Tavakoli, B. Lei, W. Su, F. Fang, Z. Fan, Nanoscale, 2017, 9, 5828.

[42] L. Gu, M. M. Tavakoli, D. Zhang, Q. Zhang, A. Waleed, Y. Xiao, K. H. Tsui, Y. Lin, L. Liao, J. Wang, Z. Fan, Adv. Mater. 2016, 28, 9713.

[43] A. Waleed, M. M. Tavakoli, L. Gu, Z. Wang, D. Zhang, A. Manikandan, Q. Zhang, R. Zhang, Y. L. Chueh, Z. Fan, Nano Lett. 2016, 17, 523.

[44] V. S. Kostko, O. V. Kostko, G. I. Makovetskii, K. I. Yanushkevich, physica status solidi (b), 2002, $229,1349$.

[45] A. A. Baloch, S. P. Aly, M. I. Hossain, F. El-Mellouhi, N. Tabet, F. H. Alharbi, Sci. Rep. 2017, 7, 11984.

[46] A. A. Asif, R. Singh, G. F. Alapatt, J. Renew. Sustain. Energy, 2015, 7, 043120.

[47] Z. Liu, Q. Chen, Z. Hong, H. Zhou, X. Xu, N. De Marco, P. Sun, Z. Zhao, Y. B. Cheng, Y. Yang, ACS Appl. Mater. Interfaces, 2016, 8, 11076. 
[48] L. Zuo, H. Guo, S. Jariwala, N. De Marco, S. Dong, R. DeBlock, D. S. Ginger, B. Dunn, M. Wang, Y. Yang, Sci. Adv. 2017, 3, 1700106. 
a
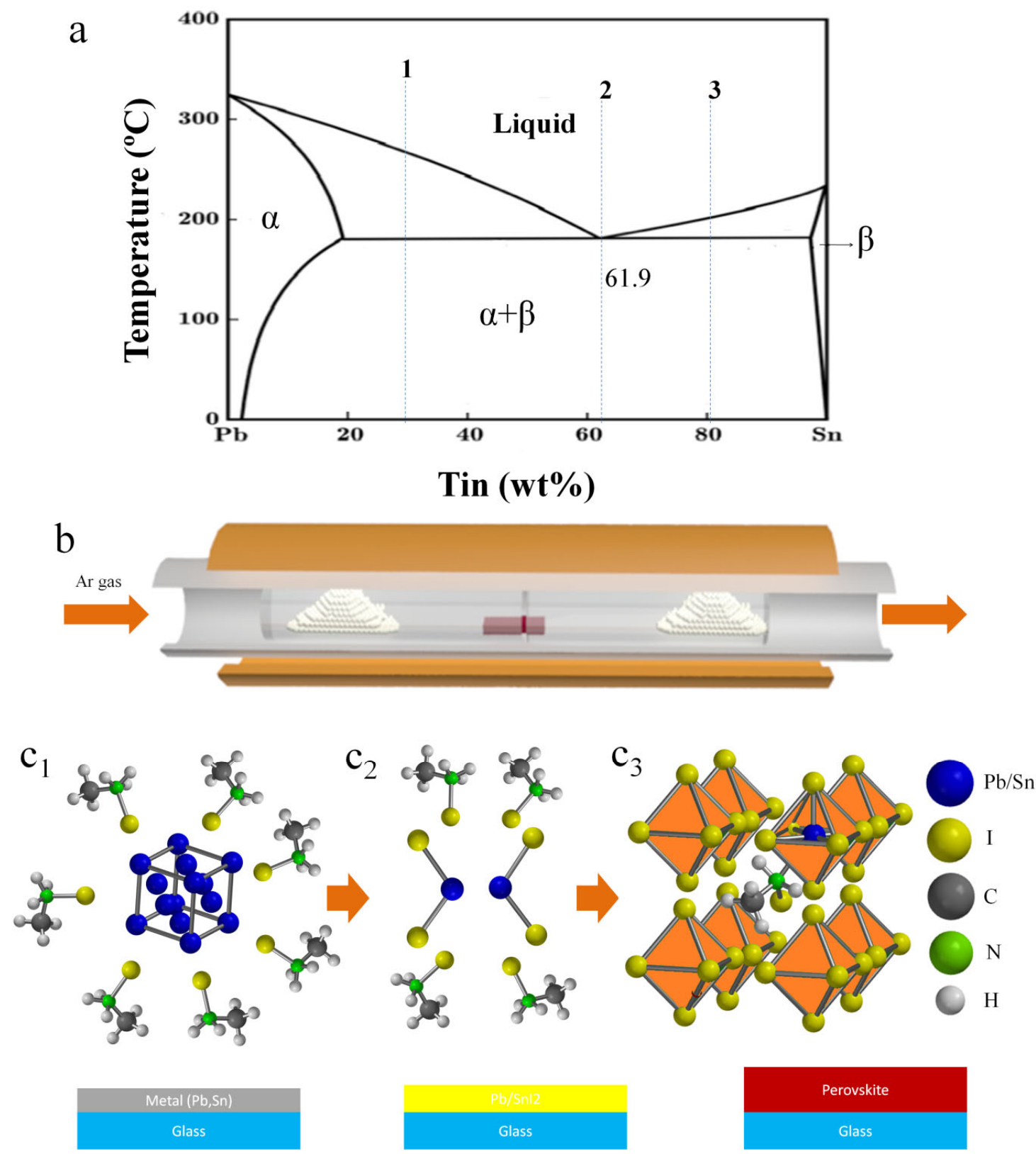

Figure 1. (a) Pb-Sn phase diagram with the selected alloys, ${ }^{40}$ (b) Schematic of CVD furnace and growth condition of perovskite film, and (c) schematics of reaction details of metals film with MAI, resulting in perovskite film formation. 


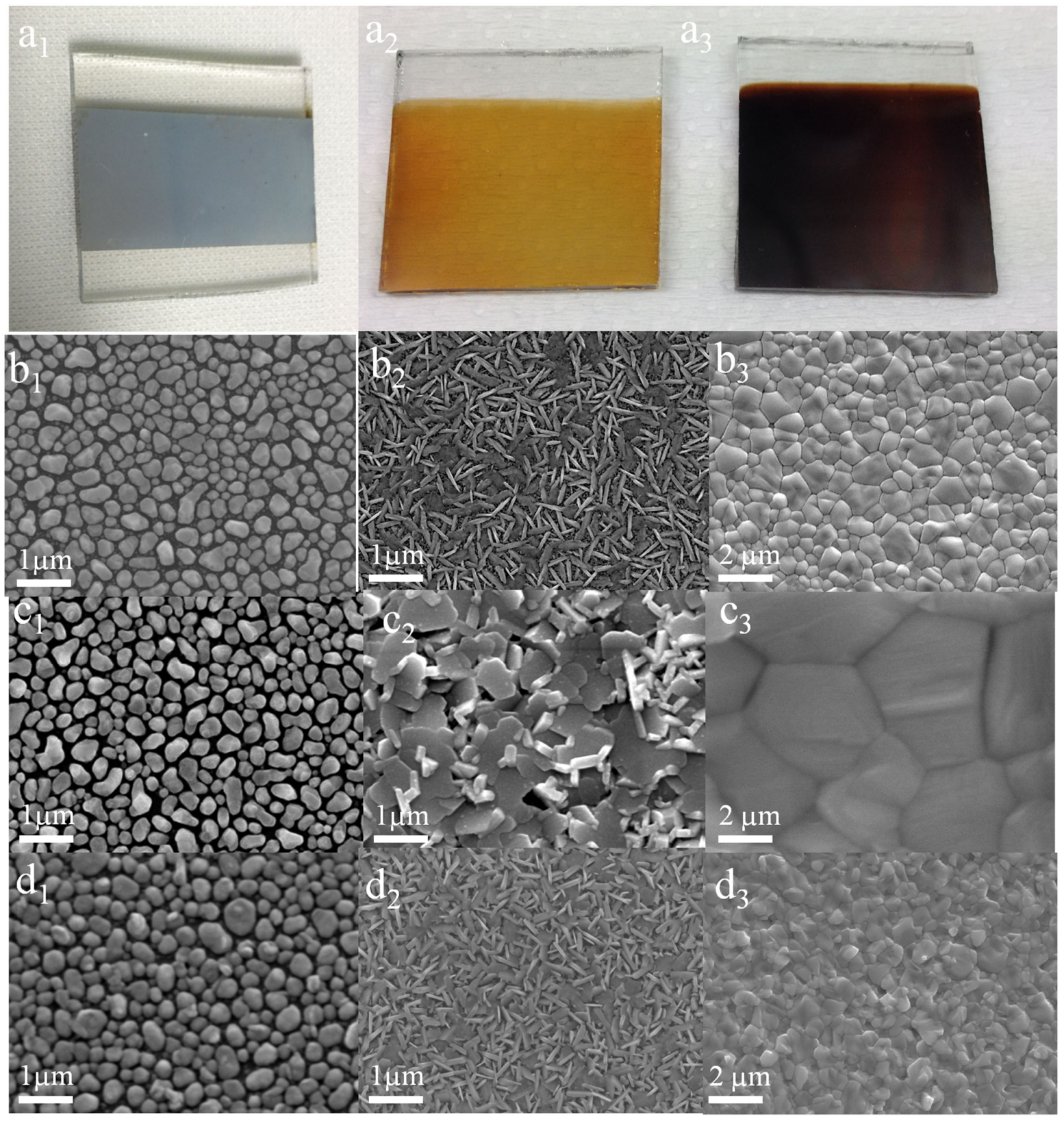

Figure 2. (a) Photographs of substrates after deposition of metal alloy ( $\mathrm{a}_{1}$ ), and after a reaction time of 20 min (intermediate $\mathrm{SnI}_{2} / \mathrm{PbI}_{2}$ phase) (a2) and $40 \mathrm{~min}$ (perovskite film) (a3). Top-view SEM images of (b $\left.\mathrm{b}_{1}\right) \mathrm{Pb}$ metal, $\left(c_{1}\right)$ eutectic alloy film, $\left(\mathrm{d}_{1}\right)$ Sn metal, and intermediate phases for $\left(b_{2}\right) \mathrm{Pb},\left(\mathrm{c}_{2}\right)$ eutectic alloy, $\left(\mathrm{d}_{2}\right) \mathrm{Sn}$ formed after 20 min reaction time, and perovskite films for $\left(b_{3}\right) \mathrm{Pb},\left(\mathrm{c}_{3}\right)$ eutectic alloy, $\left(\mathrm{d}_{3}\right) \mathrm{Sn}$ after 40 min reaction time. 

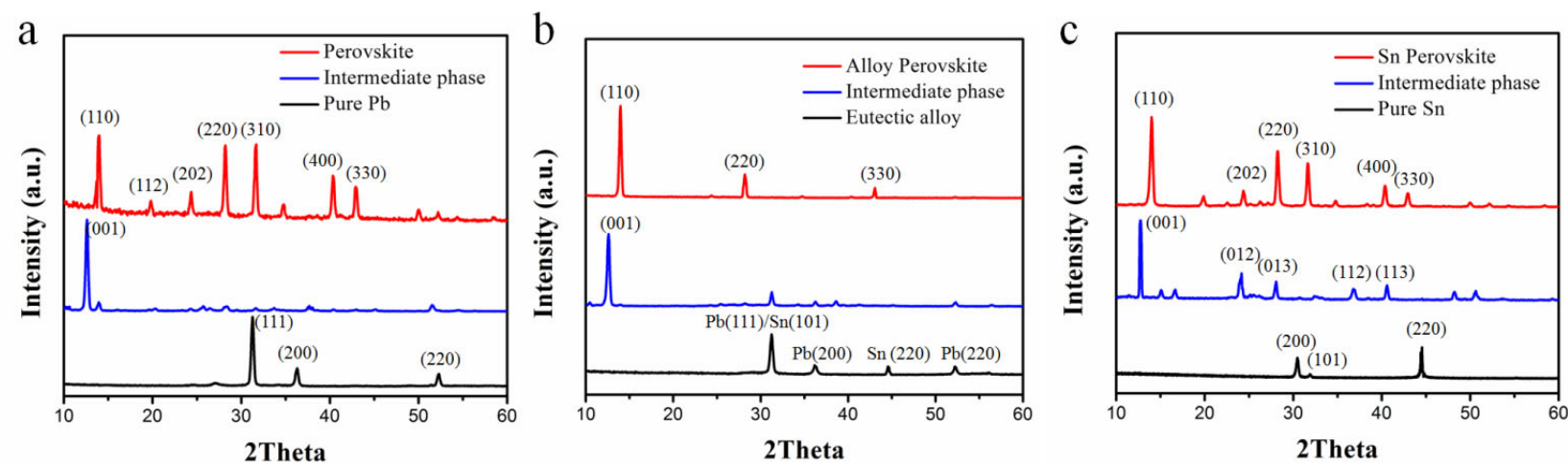

Figure 3. (a) X-ray diffraction patterns of metal films, intermediate phases after 20 min reaction, and perovskite films formed from the reaction between metal precursor and MAI after $40 \mathrm{~min}$, for different metal precursors (a) pure $\mathrm{Pb}$, (b) eutectic alloy, and (c) pure $\mathrm{Sn}$. 

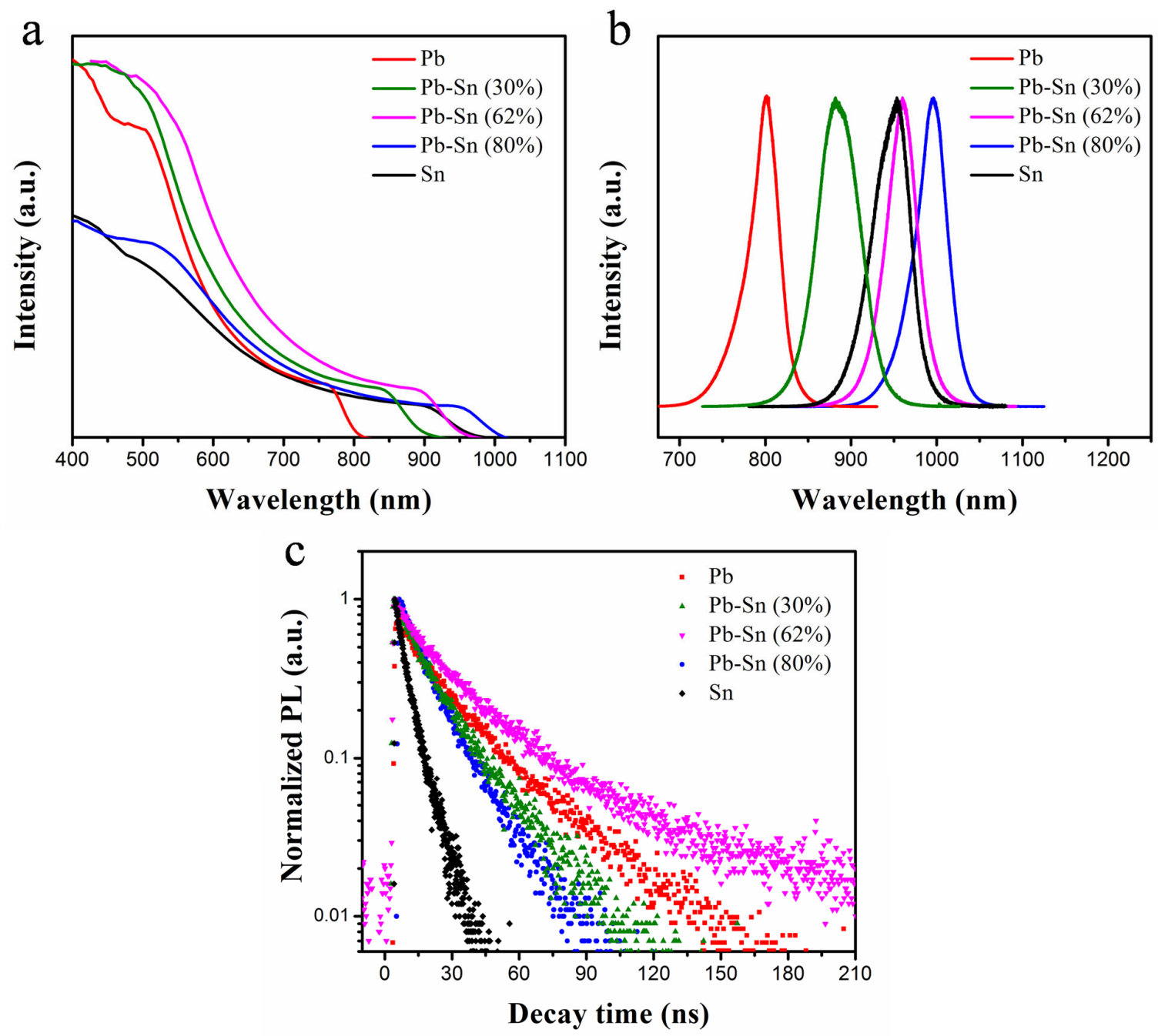

Figure 4. Optical properties of perovskite films fabricated by CVD process form metal and alloys precursors, (a) UV-Vis absorbance, (b) steady state photoluminescence, and (c) time-resolved photoluminescence (TRPL) spectra of perovskite films on glass with different concentrations of Sn metal. 

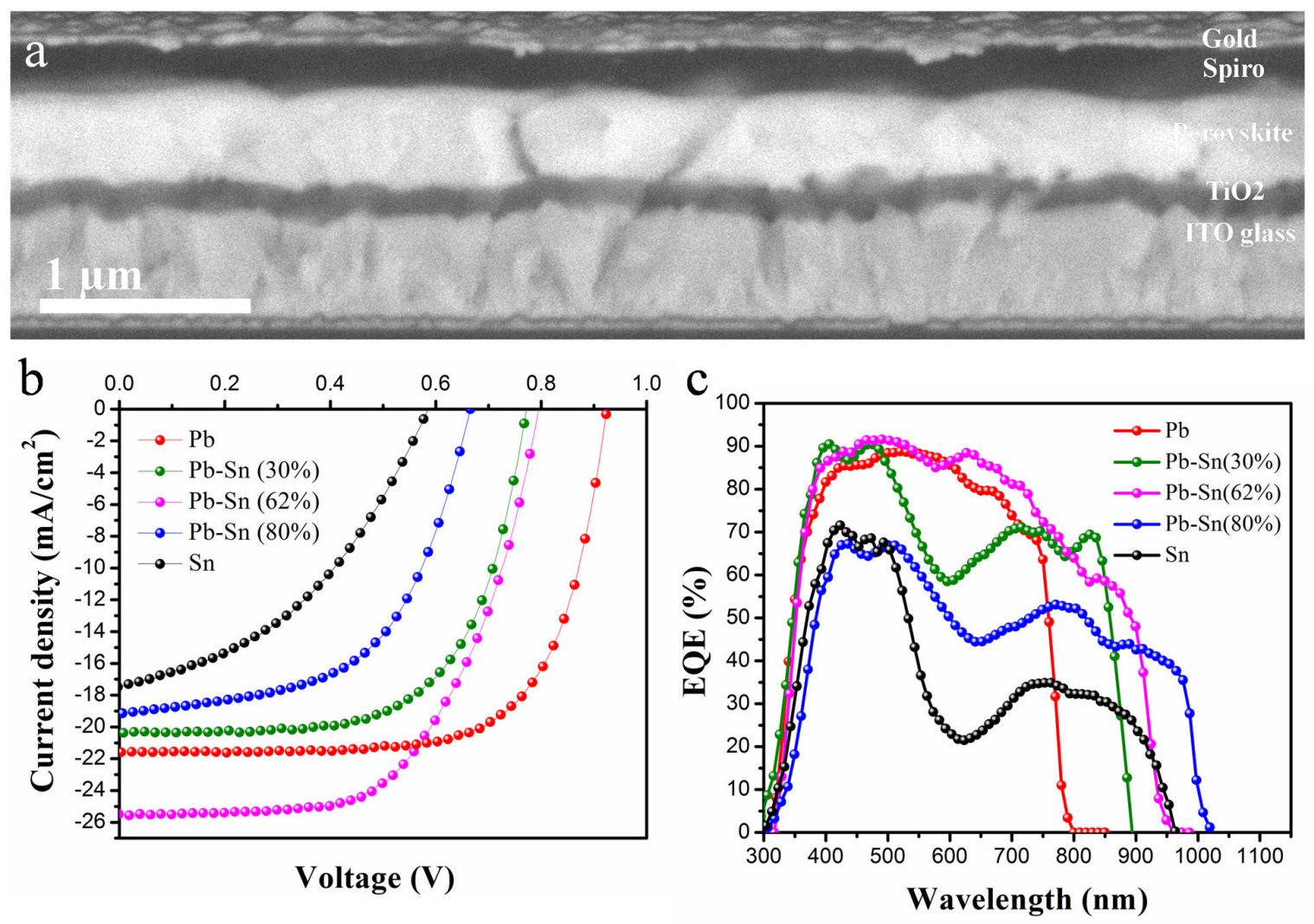

Figure 5. (a) Cross-sectional SEM image of perovskite solar cell fabricated from eutectic alloy. (b) Current density-voltage $(J-V)$ under a standard AM 1.5 light and (c) external quantum efficiency (EQE) curves of devices based on different concentrations of Sn metal. 

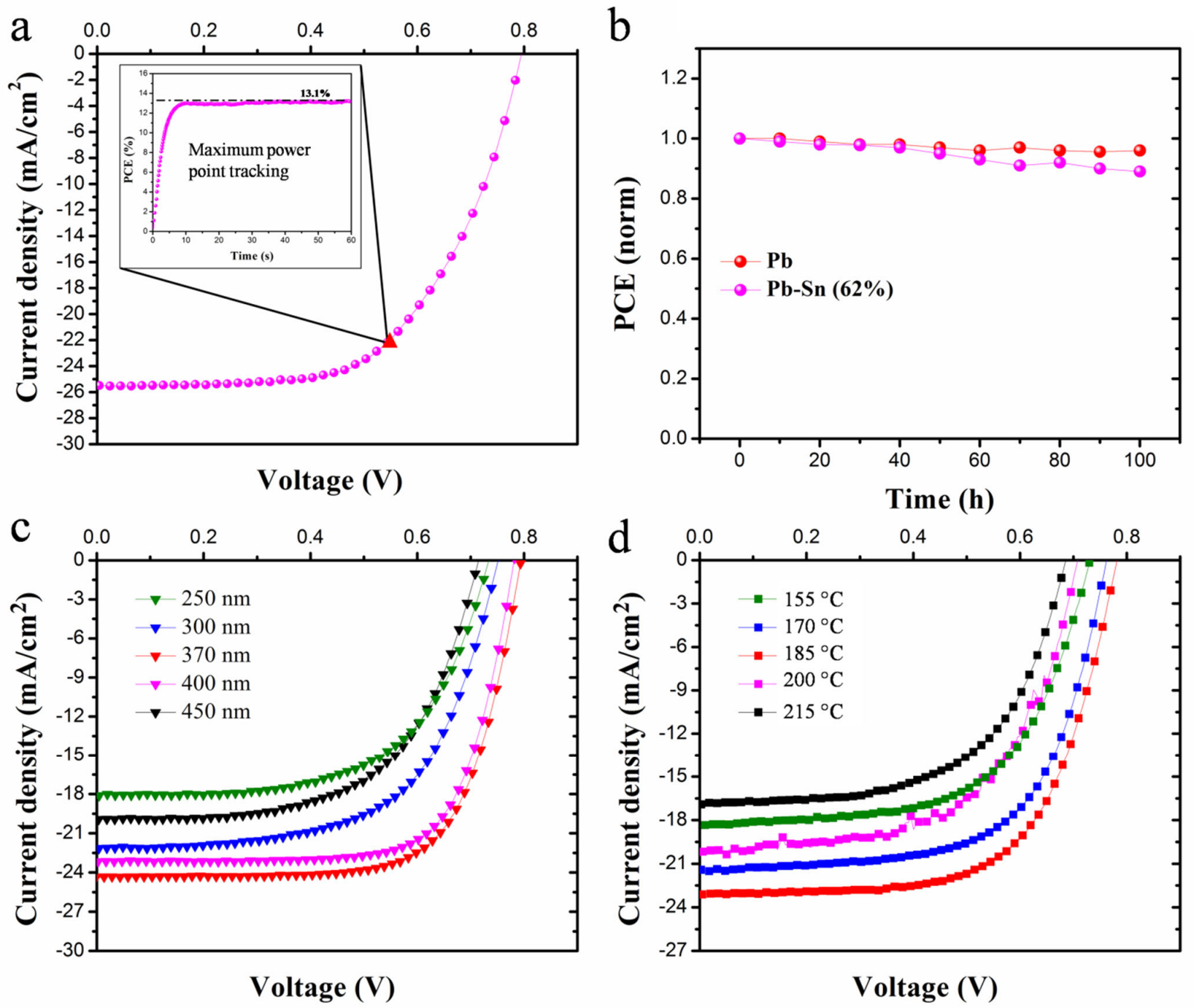

Figure 6. (a) $J-V$ curve of champion cell based on eutectic alloy with PCE of $14.04 \%$. The inset shows the scan rate-independent maximum power point tracking for 60 seconds, resulting in a stabilized PCE of 13.1\%. (b) Stability test of solar cell devices based on pure $\mathrm{Pb}$ and eutectic alloy for 100 hours at room temperature, after sealing them with epoxy-glue. (Note that each dot is the average values of 10 devices) (c) $J-V$ cures of devices based on eutectic alloy for different thicknesses of perovskite film. (d) $J-V$ curves of perovskite devices based on eutectic alloy fabricated at $155,170,185,200$, and $215^{\circ} \mathrm{C}$ temperatures. 
Table 1. Average weight percentage values of $\mathrm{Pb}-\mathrm{Sn}$ alloys (fabricated by two-step evaporation process) measured with EDAX analysis

\begin{tabular}{|c|c|c|}
\hline Alloys & Sn & $\mathrm{Pb}$ \\
\hline $1(\mathrm{~Pb}-30 \mathrm{wt} \% \mathrm{Sn})$ & 29.73 & 70.45 \\
\hline $2(\mathrm{~Pb}-62 \mathrm{wt} \% \mathrm{Sn})$ & 61.67 & 37.67 \\
\hline $3(\mathrm{~Pb}-80 \mathrm{wt} \% \mathrm{Sn})$ & 81.1 & 19.46 \\
\hline
\end{tabular}

Table 2. Figure of merits for prepared photovoltaic devices with different concentrations of Sn metal

\begin{tabular}{|c|c|c|c|c|c|}
\hline Device & $\begin{array}{c}V_{o c} \\
(\mathrm{~V})\end{array}$ & $\begin{array}{c}J_{s c} \\
\left(\mathrm{~mA} / \mathrm{cm}^{2}\right)\end{array}$ & $\begin{array}{c}\text { FF } \\
(\%)\end{array}$ & $\begin{array}{c}\text { PCE (Average PCE) } \\
(\%)\end{array}$ & $\begin{array}{c}J_{s c} \text { from EQE } \\
\left(\mathrm{mA} / \mathrm{cm}^{2}\right)\end{array}$ \\
\hline $\mathrm{Pb}$ & 0.921 & 21.6 & 71.3 & $14.21(13.83)$ & 21.7 \\
\hline $\mathrm{Pb}-30 \% \mathrm{Sn}$ & 0.772 & 20.3 & 66.4 & $10.41(9.71)$ & 19.8 \\
\hline $\mathrm{Pb}-62 \% \mathrm{Sn}$ & 0.796 & 25.5 & 69.2 & $14.04(13.62)$ & 24.6 \\
\hline $\mathrm{Pb}-80 \% \mathrm{Sn}$ & 0.673 & 19.1 & 55.4 & $7.07(6.15)$ & 18.7 \\
\hline $\mathrm{Sn}$ & 0.592 & 17.7 & 44.1 & $4.62(3.28)$ & 16.4 \\
\hline
\end{tabular}




\section{TOC}
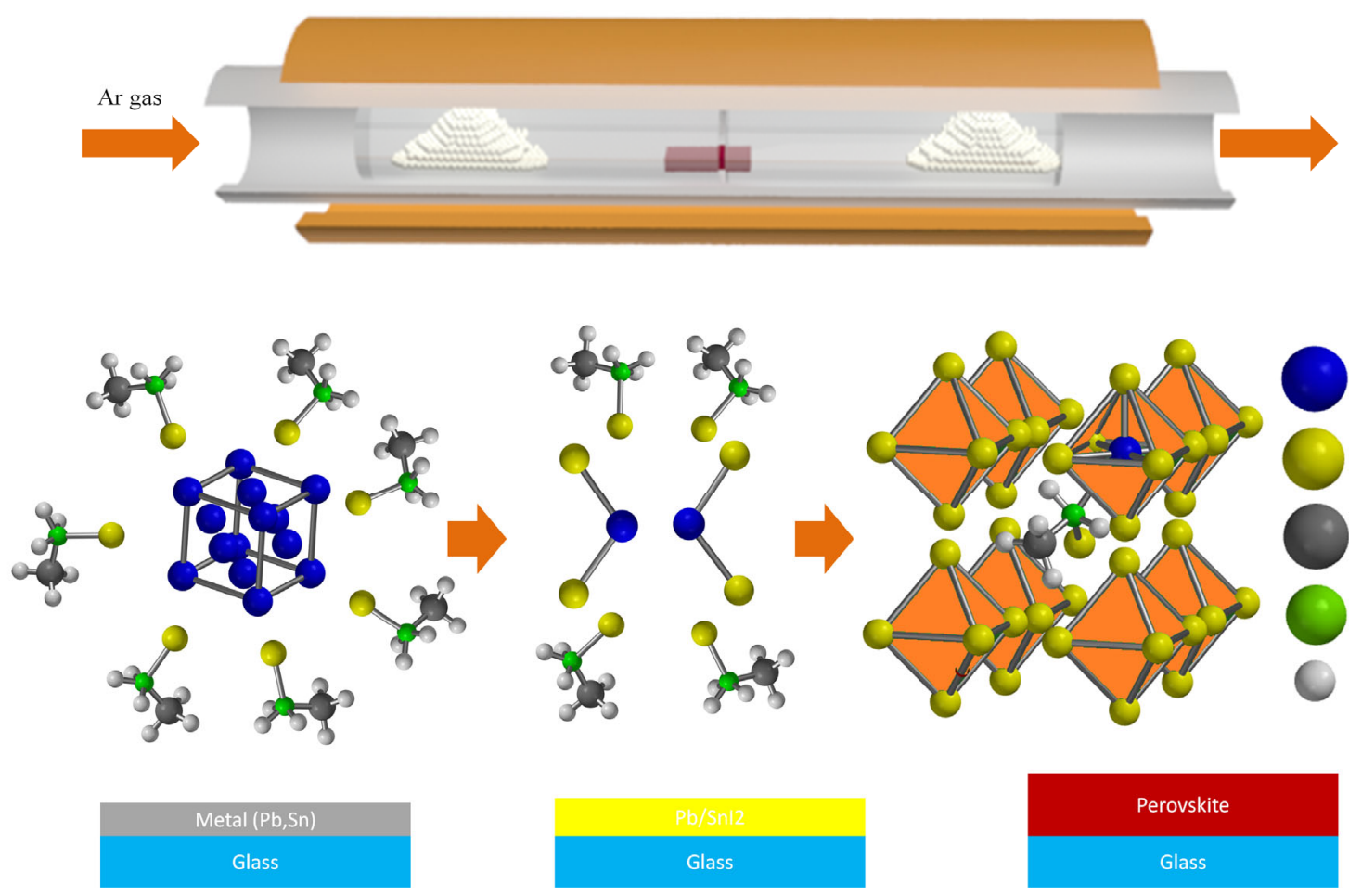

In this work, Sn-rich perovskite solar cells with large grains were fabricated from $\mathrm{Pb}-\mathrm{Sn}$ eutectic alloy in the liquid phase by using CVD technique, resulting in a device PCE of $14.04 \%$ which is comparable with that of a pure $\mathrm{Pb}$ device and among the highest for $\mathrm{Sn}$-rich binary $\mathrm{Sn} / \mathrm{Pb}$ metal perovskite solar cells. 